\title{
Integration of New Neurons into Functional Neural Networks
}

\author{
Victor Ramirez-Amaya, ${ }^{1,3}$ Diano F. Marrone, ${ }^{1}$ Fred H. Gage ${ }^{4}$ Paul F. Worley, ${ }^{5}$ and Carol A. Barnes ${ }^{1,2}$ \\ ${ }^{1}$ Arizona Research Laboratories Division of Neural Systems, Memory, and Aging and 2Departments of Psychology and Neurology, University of Arizona, \\ Tucson, Arizona 85724, ${ }^{3}$ Departamento de Neurobiologia Conductual y Cognitiva, Instituto de Neurobiología, Universidad Nacional Autónoma de México, \\ Querétaro 76230, México, ${ }^{4}$ Laboratory of Genetics, The Salk Institute for Biological Studies, La Jolla, California 92037, and ${ }^{5}$ Departments of Neuroscience \\ and Neurology, Johns Hopkins University, Baltimore, Maryland 21218
}

\begin{abstract}
Although it is established that new granule cells can be born and can survive in the adult mammalian hippocampus, there remains some question concerning the functional integration of these neurons into behaviorally relevant neural networks. By using high-resolution confocal microscopy, we have applied a new strategy to address the question of functional integration of newborn neurons into networks that mediate spatial information processing and memory formation. Exploration-induced expression of the immediate-early gene Arc in hippocampal cells has been linked to cellular activity observed in electrophysiological recordings under the same behavioral conditions. We investigated whether mature (5-month-old), newborn granule cells express Arc in response to a discrete spatial experience by detecting the expression of Arc in combination with NeuN (neuron-specific nuclear protein)-positive and bromodeoxyuridine-positive cells. We found that mature new granule cells do indeed express Arc in response to an exploration experience, supporting the idea that these cells are well integrated into hippocampal circuits. The proportion of mature newborn neurons that expressed Arc in response to exploration, however, was significantly higher $(\sim 2.8 \%)$ than the proportion of cells that expressed Arc in the already existing population of granule cells $(\sim 1.6 \% ; p<0.01)$. This finding extends previous data suggesting that the cellular physiology of newborn granule neurons differs from that of the existing population by indicating that these properties are retained in mature adult-generated neurons. Thus, these data have interesting implications for network models of spatial information processing and the role of hippocampal circuits in memory, indicating that mature new neurons are selectively recruited into hippocampal cell assemblies in higher proportions than older cells.
\end{abstract}

Key words: neurogenesis; immediate-early genes; Arg3.1; spatial behavior; dentate gyrus; place cells

\section{Introduction}

One of the most remarkable discoveries in the recent history of neuroscience is that new neurons are born in the adult mammalian brain (Altman and Das, 1965; Kaplan and Hinds, 1977; Eriksson et al., 1998). Adult neurogenesis in mammals is observed mainly in two regions, the olfactory bulb and the hippocampal dentate gyrus (DG). New neurons in the hippocampus originate from stem-like cells (Weiss et al., 1996) located in the subgranular layer of the DG, and they migrate into the granular zone (Kuhn et al., 1996), develop dendritic projections (Ribak et al., 2004), and extend their axons along the expected trajectory (Stanfield and Trice, 1988), reaching the dendrites of CA3 pyramidal cells (Hastings and Gould, 1999). It has also been shown that, given adequate time for these newborn granule neurons to mature, they develop synaptic responsiveness and other electrophysiological

Received May 24, 2006; revised Sept. 19, 2006; accepted Oct. 9, 2006.

This work was supported by National Institute on Aging Grant AG009219 and Human Frontier Science Program Grant LTF000112-2002-C. We thank Frank Houston for technical assistance and Dr. Dorothy Pless for helpful comments on this manuscript.

Correspondence should be addressed to Carol A. Barnes, Arizona Research Laboratories Division of Neural Systems, University of Arizona, Life Sciences North, Room 384, Tucson, AZ 85724. E-mail: carol@nsma.arizona.edu. D01:10.1523/JNEUROSCI.2195-06.2006

Copyright $\odot 2006$ Society for Neuroscience $\quad$ 0270-6474/06/2612237-05\$15.00/0 properties similar to those of existing granule cells (Song et al., 2002; van Praag et al., 2002).

Adult neurogenesis may be of great relevance for neural plasticity underlying animal cognition, because the number of newborn granule cells have been shown to correlate with effective hippocampus-dependent memory (Shors et al., 2001; Shors, 2004). Here we address the question of whether adult-born granule neurons show gene expression patterns indicative of functional network activity patterns of hippocampal cells. The immediate-early gene $A r c$ and its protein product are induced by spatial exploration in the same proportion of cells as observed during electrophysiological recordings (Guzowski et al., 1999; Vazdarjanova et al., 2002; Ramirez-Amaya et al., 2005) and therefore can be used to monitor hippocampal cell activity linked to spatial behaviors. Thus, by evaluating the pattern of Arc expression in bromodeoxyuridine (BrdU)-positive neurons after a discrete behavioral epoch, Arc detection can be an effective means to identify individual neurons that participate in a given behavioral experience. In the present experiment, triple fluorescent immunohistochemistry for Arc, neuron-specific nuclear protein $(\mathrm{NeuN})$, and BrdU was used, and high-resolution confocal imaging was used to identify the cells that respond to behavioral exploration by expressing Arc (Ramirez-Amaya et al., 2005) and 
those cells in which BrdU and NeuN colocalize. This allowed the detection of those mature neurons that underwent cell division during a $5 \mathrm{~d}$ window of BrdU availability 5 months before exploration.

When both mature newborn granule cells (those that incorporate BrdU) and already existing granule cells were examined, both populations of granule cells were observed to express Arc in response to spatial exploration. This was revealed by the differences between caged and exploration-treated animals in the proportion of Arc-expressing neurons. Mature newborn granule cells, however, express Arc in a significantly greater proportion in response to spatial exploration. This finding provides compelling evidence for their integration into functional hippocampal networks.

\section{Materials and Methods}

Subjects. Eight Fisher-344 rats (Harlan Sprague Dawley, Indianapolis, IN), 6 months of age, living in an inverted $12 \mathrm{~h}$ light/dark cycle (lights on at 10:00 P.M. and off at 10:00 A.M.), were housed individually and maintained with water and food ad libitum.

BrdU administration. All animals received daily intraperitoneal injections of $50 \mathrm{mg} / \mathrm{kg}$ BrdU (Sigma, St. Louis, MO) over a period of

$5 \mathrm{~d}$. Afterward, the animals were kept undisturbed in their home cages for 5 months.

Spatial exploration. Five months after the last BrdU injection, five animals underwent a 5 min exploration session, as described previously (Ramirez-Amaya et al., 2005). All animals were handled for $8 \mathrm{~d}$ before the exploration session, but the day before the exploration session, the animals were kept undisturbed. The exploration environment was a square open box, $61 \times 61 \mathrm{~cm}$ with 20 -cm-high walls, partitioned into nine grids. Each rat was placed in the center of one of the grids and moved to the center of a different grid every $15 \mathrm{~s}$ so that each of the grids was visited two or three times during the 5 min exploration session. Immediately after the exploration session, the animal was placed back in its home cage and kept undisturbed. The remaining three rats were kept in their home cages (caged) and were killed at the same time as the rats given behavioral treatment.

Brain extraction. Thirty minutes after the exploration session, the animals were killed by decapitation. The brain was quickly and carefully extracted and frozen in 2-methylbutane (Sigma) immersed in a slurry of dry ice and ethanol. The brains were stored at $-70^{\circ} \mathrm{C}$.

Blocking and sectioning. Brain hemisections containing the left dorsal hippocampus from six to eight rats were molded in a block with TissueTek optimal cutting temperature compound (Miles, Elkhart, IN), such that the block contained brains from all groups. The position of each group was different in each block. The blocks were cryosectioned into 20- $\mu \mathrm{m}$-thick coronal sections, captured on Superfrost Plus slides (VWR, Batavia, IL), dried, and stored at $-70^{\circ} \mathrm{C}$.

Immunohistochemistry. Twenty-five slides from the block were selected from the medial portion of the dorsal hippocampus. The tissue was fixed in $2 \%$ paraformaldehyde, $\mathrm{pH} 7.4$, for $5 \mathrm{~min}$, washed in TBS, $\mathrm{pH} 7.0$, and quenched in TBS with $2 \% \mathrm{H}_{2} \mathrm{O}_{2}$ for 15 min. After blocking with tyramide signal amplification (TSA) kit blocking buffer (PerkinElmer Life Sciences, Emeryville, CA), the slides were sequentially incubated for the first detection with mouse biotinylated anti-NeuN antibody (1:2000; Millipore, Bedford, MA), for the second detection with polyclonal rabbit anti-Arc antibody (1:800; a gift from P.F.W.'s laboratory), and for the third detection with mouse anti-BrdU monoclonal antibody (1:100;
Roche Products, Welwyn Garden City, UK). Before the detection of Arc (for details, see Ramirez-Amaya et al., 2005), the tissue was permeabilized with acetone/methanol (50:50, v/v; Sigma) at $4^{\circ} \mathrm{C}$ for $5 \mathrm{~min}$. For the detection of BrdU, the DNA was denatured with a $50 \%$ formamide in $2 \times$ SSC buffer (Sigma) at $65^{\circ} \mathrm{C}$ for $2 \mathrm{~h}$, washed in $2 \times$ SSC for $10 \mathrm{~min}$, incubated in $2 \mathrm{~N} \mathrm{HCl}$ at $37^{\circ} \mathrm{C}$ for $30 \mathrm{~min}$, and washed in $0.1 \mathrm{M}$ boric acid, $\mathrm{pH} 8.5$, for $10 \mathrm{~min}$. Biotinylated anti-NeuN was detected with the antibody amplification kit (Vector Laboratories, Burlingame, CA) and the cyanine-5 (Cy5) TSA fluorescence system (PerkinElmer); rabbit anti-Arc was detected with biotinylated anti-rabbit antibody (Vector Laboratories). The slides were then blocked with the antibody-blocking system (Vector Laboratories) and amplified with the antibody amplification kit, and the signal was finally detected with the Cy3 TSA fluorescence system (PerkinElmer). Mouse IgG was blocked using the mouse-on-mouse blocking kit (Vector Laboratories) before detection of BrdU. The mouse anti-BrdU antibody was detected with a biotinylated anti-mouse antibody in which the signal was amplified using an antibody amplification kit, and it was finally observed using the FITC TSA fluorescence system (PerkinElmer). No staining was detected in the absence of the primary or secondary antibodies.

Confocal imaging and analysis. Images were taken using a Zeiss (Thornwood, NY) SM 510NLO-meta multiphoton/confocal microscope equipped with three lasers, a $488 \mathrm{~nm}$ argon laser, and 543 and $633 \mathrm{~nm}$ helium/neon lasers. With the use of a $25 \times$ water-immersion objective, image stacks were collected from the entire thickness of the tissue (20 $\mu \mathrm{m}$ ), over the entire DG for each animal. The imaging parameters were set using the caged control on any given slide, and the rest of the brains were taken with the same parameters. Fifteen whole DG regions, taken from serial sections, were imaged for each animal. This corresponds to a dorsoventral length of $300 \mu \mathrm{m}$ from the dorsal hippocampus. The most anterior section was taken $\sim 5.5 \mathrm{~mm}$ from the interaural plane.

Each DG was reconstructed with Adobe Photoshop (Adobe Systems, San Jose, CA) using the middle plane image from each stack, resulting in a two-dimensional image (Fig. $1 A, C$ ). This image was used as the reference image, and the $25 \times$ image stack was used to identify the cells in which NeuN and BrdU are colocalized, as well as Arc-positive cells. Each 
A

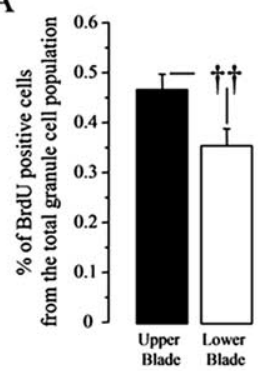

C

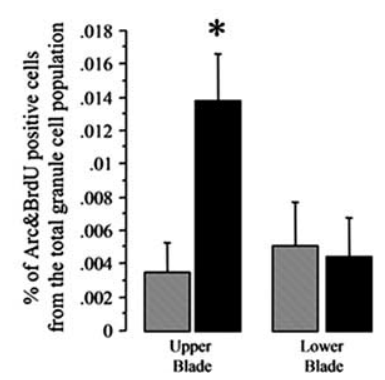

B

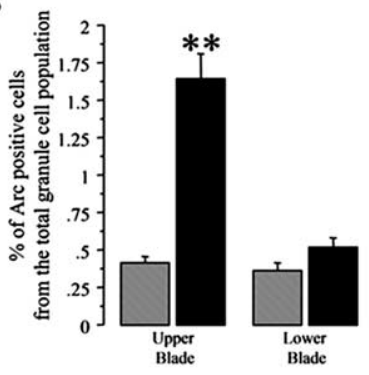

D

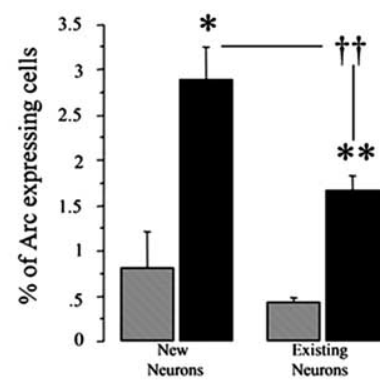

Figure 2. $\quad \boldsymbol{A}$, The proportion of granule neurons $(\mathrm{NeuN}+)$ in which BrdU was detected, from the total population of granule cells. Differences were found in the upper versus lower blades of the DG. $\boldsymbol{B}$, The proportion of Arc-positive cells detected from the total population of granule cells. Significant differences were found in Arc expression between exploration and caged control groups only in the upper blade. C, The proportion of cells that show BrdU and Arc colocalization in the upper and lower blades of the DG. Note the low, but statistically reliable, proportion of cells that showed both Arc and BrdU labeling. D, The proportion of Arc-expressing cells in the population of newborn neurons is compared with the proportion of Arc-expressing cells in the population of already existing granule neurons. Significant differences were found in the proportion of Arc-expressing cells between newborn and already existing granule cells only in the exploration group. ANOVA, ${ }^{*} p<0.05$ and ${ }^{* *} p<0.01 ; t$ test, ${ }^{++} p<0.01$. Error bars indicate SEM.

BrdU-positive cell colocalizing with NeuN was considered a new neuron, and the Arc-positive cells were considered the activated neurons. Each cell classified as BrdU/NeuN positive, Arc positive, or both (Fig. 1B,D) was annotated in the reference image. Duplicate cells found in adjacent image stacks were discarded to avoid overcounting. After all $25 \times$ image stacks were observed and all positive cells were classified, the volume of the granular cell layer was calculated in the reference image, from which the number of granule cells was estimated, as described previously (Ramirez-Amaya et al., 2005). The proportion of granule cells expressing either Arc, BrdU, or both Arc and BrdU together were calculated using the estimated number of total granule cells. This estimate was $\sim 53,000$ cells per animal in both blades. The proportion of mature new neurons expressing Arc represents the number of activated cells in the BrdU population, whereas the proportion of Arc-expressing cells in the already existing population represents the number of active cells in the nonBrdU population of granule cells.

Statistics. Either $t$ tests or one-way ANOVAs were used where appropriate to compare the proportion of BrdU/NeuN- and Arc-expressing cells in the different conditions.

\section{Results}

New granule cells were observed mainly in the upper blade

The newborn granule cells were observed mainly within the granule cell layer of the DG, in the dorsal hippocampus. In the upper blade, $\sim 0.45 \%$ of the granule cell population were new neurons born 5 months earlier. In the lower blade, only $\sim 0.35 \%$ of the granule cells contained NeuN and BrdU. A one-way ANOVA revealed that these values are significantly different $\left(t_{(7)}=3.342\right.$; $p<0.01)$ (Fig. 2A).

Neurogenesis is not affected by a single acute exploration session

In the upper blade, a statistically similar $\left(F_{(1,6)}=0.214 ; p=0.66\right)$ proportion of BrdU cells were observed in the cage (0.446 \pm $0.025)$ and in the exploring $(0.478 \pm 0.051)$ animals. Similarly, data from the lower blade reveal comparable $\left(F_{(1,6)}=0.494 ; p=\right.$ 0.5086) proportions of BrdU-positive cells in the caged ( $0.322 \pm$ $0.074)$ and in the exploration $(0.374 \pm 0.112)$ groups. Thus, our behavioral paradigm induces no detectable difference in cell survival.

This observation is not surprising, given that BrdU injections (and thus incorporation) occurred 5 full months before the exploration experience. During this long delay, animals in all conditions remained undisturbed in their home cage. Although exercise and/or spatial experience can influence the proliferation rate and survival of newborn granule cells in the DG, this is typically observed when BrdU is administered during (or a few weeks before) the behavioral experience (Gould et al., 1999; van Praag et al., 1999; Ambrogini et al., 2000).

\section{Arc expression after exploration}

As observed previously (Chawla et al., 2005; Ramirez-Amaya et al., 2005), granule cells in the DG respond to spatial exploration by expressing Arc protein only in a small proportion of cells $(\sim 1.75 \%)$, located primarily in its upper blade (Fig. $2 B$ ). When the number of Arc-positive cells between behavior-treated animals and caged controls were compared, significant differences were found only in the upper blade region $\left(F_{(1,6)}=30.86\right.$; $p<$ 0.001).

\section{Arc expression in BrdU-positive cells}

In a given rat that had exploration treatment, $\sim 3$ granule cells out of a population of 20,000 counted, showed BrdU label colocalized with Arc protein expression $(0.014 \% \pm 0.002)$; whereas in the caged animals, the colocalization of Arc and BrdU is much lower $(<0.005 \%)$ (Fig. 2C). Statistical analysis reveals that there are significant differences between exploration-treated and caged animals in the number of Arc-expressing cells that had previously incorporated $\mathrm{BrdU}\left(F_{(1,6)}=7.143 ; p<0.04\right)$. This significant increase in the likelihood of colocalization between Arc and BrdU indicates that mature new neurons in the DG do respond to exploration by expressing Arc.

The relevant question, however, was whether the proportion of mature newborn granule cells responding to exploration was the same as that of the already existing granule cell population. The data indicate that the overall proportion of granule cells that respond to spatial exploration is 1.639\% (including both BrdU and non-BrdU cells). The BrdU-containing cells represent $0.45 \%$ of the population and non-BrdU cells represent $99.55 \%$. When the BrdU cell population is examined alone, $2.855 \%$ express Arc in response to the exploration treatment (Fig. 2D) compared with $1.633 \%$ of the non-BrdU cell population alone. This difference is statistically significant $\left(T_{(4)}=4.873 ; p<0.01\right)$ and suggests that mature newborn granule cells have a lower threshold for Arc expression than do the existing population of granule cells.

Although there is a small, nonsignificant trend for the presence of increased Arc expression in BrdU-labeled cells in caged control animals (Fig. 2D), these data are, in fact, consistent with the notion that newborn granule cells are more excitable and consequently more responsive to exploration, even when this exploration occurs in the home cage environment.

During their time undisturbed in the home cage, rats will 
(although relatively infrequently) explore the environment, presumably producing theta oscillations in the hippocampus, and thus a state in which Arc expression occurs. However, massed exposure to an environment (as would occur in an animal left undisturbed in his home cage) significantly attenuates Arc expression (Guzowski et al., 2006) and thus produces Arc expression in a small population of cells. BrdU-positive cells will be selectively recruited into these home cage place-field ensembles as well as those generated by the more robust response to a novel environment, and this small increase in the proportion of BrdUpositive cells active in the home cage is to be expected.

\section{Discussion}

Two main novel findings arise from the present data. First, mature new granule cells do respond to behavioral exploration, as do already existing granule cells, by expressing the immediate-early gene Arc. Second, a greater proportion of the new (BrdUpositive) granule cells responds to spatial exploration compared with the already existing (non-BrdU) population. These data suggest that, at least at 5 months after BrdU incorporation, these new neurons express Arc selectively when activated by behaviors that result in place-field activation in granule cells, as recorded in electrophysiological experiments in environments of similar sizes (Jung and McNaughton, 1993; Shen et al., 1998; Gothard et al., 2001). The present results greatly extend previous data because the current study has used a paradigm that permits the measurement of neuronal activity in mature, newly generated granule cells, in the presence of physiologically relevant levels of stimulation induced by learning experience.

Although previous observations indicate that new granule neurons integrate anatomically into the network by developing appropriate dendritic (Ambrogini et al., 2004; Fujioka et al., 2004; Rao and Shetty, 2004; Esposito et al., 2005; Rao et al., 2005; Ge et al., 2006; Overstreet-Wadiche et al., 2006a,b) and axonal (Hastings and Gould, 1999) structures and respond to synaptic input (van Praag et al., 2002; Ambrogini et al., 2004; Esposito et al., 2005; Ge et al., 2006; Overstreet-Wadiche et al., 2006a,b), these studies have primarily compared immature newborn granule cells to mature granule cells. In fact, many of these studies used morphological, electrophysiological, and/or biochemical markers of newborn cells that dissipate relatively quickly as the granule cell matures (Overstreet-Wadiche and Westbrook, 2006). Primarily for this reason, critical questions remain about the network behavior of newborn granule cells in vivo.

Young, newborn granule cells $(\sim 3$ weeks old $)$ exhibit an enhanced excitability and increased $\mathrm{Ca}^{2+}$ conductance (Ambrogini et al., 2004; Schmidt-Hieber et al., 2004) and a lower threshold for LTP induction (Schmidt-Hieber et al., 2004) than their mature, already existing granule cell neighbors. It is not known, however, whether these unique properties of young BrdU-positive neurons remain beyond 3 weeks (Song et al., 2005). There is evidence that, given sufficient survival time (i.e., 4 months), newborn granule cells may develop electrophysiological properties similar to those of existing neurons (van Praag et al., 2002); however, the plasticity of these newly generated granule cells during spatial processing have yet to be examined.

Because the detection of Arc protein expression after exploration is a reliable method for monitoring cellular activity induced by spatial behavior in hippocampal cells, this method permits us to address, for the first time, whether newborn granule cells retain behaviorally important physiological distinctions compared with their neonatally generated counterparts after long maturation and survival delays. Although mature, new granule cells have been shown previously to express cFos after spatial learning (Jessberger and Kempermann, 2003), cFos expression has not yet been related directly to neural activity, nor is $\mathrm{CFos}$ a specific marker for neurons (Arenander et al., 1989). In contrast, the proportion of cells expressing Arc after spatial exploration (Guzowski et al., 1999; Vazdarjanova et al., 2002; Ramirez-Amaya et al., 2005) is the same as that observed in electrophysiological recordings under the same behavioral conditions (Barnes et al., 1990; McNaughton et al., 1994; Qin et al., 1997), and Arc is expressed only in neurons (Vazdarjanova et al., 2006). Moreover, the expression of the protein product of Arc occurs in the same group of cells that express Arc mRNA after exploration in two similar environments (Ramirez-Amaya et al., 2005), indicating that Arc is translated into protein with high fidelity.

The data presented here suggest that newborn granule cells retain enhanced plasticity, even once they have matured to the point where they are electrophysiologically indistinguishable from neonatal-generated cells (van Praag et al., 2002; OverstreetWadiche and Westbrook, 2006). The greater response to behaviorally induced Arc activation is, at least, consistent with higher excitability (Ambrogini et al., 2004; Schmidt-Hieber et al., 2004) and a lowered overall threshold for spiking and suggests that this enhanced plasticity has behaviorally relevant implications for the expression of place fields and thus the processing of spatial information.

It is unclear, however, how these properties are affected by physical exercise or other behavioral stimulation administered in previous experiments (van Praag et al., 2002), an issue that is especially relevant given recent evidence that the functional maturation of new neurons in the adult brain is activity dependent (Overstreet-Wadiche et al., 2006b). In the present experiment, all animals were kept undisturbed during the 5 month period, with the exception of the last hour before they were killed (a period insufficient to induce experience-dependent changes in cell survival), and thus their maturation state may differ from animals given behavioral treatment in intervening intervals (van Praag et al., 2002). Furthermore, both the BrdU-positive and non-BrdU neurons in those animals that explored a novel environment were subjected to the same behavioral activity experience immediately before the animals were killed, within the same animal. Thus, any difference between cell electrophysiological properties were not a result of differential experience.

Despite these open questions, the participation of mature newborn granule cells in behavior-induced expression of Arc, which is required for spatial memory consolidation and lasting forms of plasticity (Guzowski et al., 2000) and is targeted to specific dendritic domains (Steward and Worley, 2001), provides compelling evidence that recently born neurons participate in behaviorally relevant hippocampal networks. Because a greater proportion of new granule cells respond to behavior-driven gene expression than their existing counterparts, these new cells may play a special role in the stabilization of synaptic changes required for memory consolidation.

\section{References}

Altman J, Das GD (1965) Autoradiographic and histologic evidence of postnatal neurogenesis in rats. J Comp Neurol 124:319-335.

Ambrogini P, Cuppini R, Cuppini C, Ciaroni S, Cecchini T, Ferri P, Sartini S, Del Grande P (2000) Spatial learning affects immature granule cell survival in adult rat dentate gyrus. Neurosci Lett 286:21-24.

Ambrogini P, Lattanzi D, Ciuffoli S, Agostini D, Bertini L, Stocchi V, Santi S, Cuppini R (2004) Morpho-functional characterization of neuronal cells at different stages of maturation in granule cell layer of adult rat dentate gyrus. Brain Res 1017:21-31. 
Arenander AT, de Vellis J, Herschman HR (1989) Induction of c-fos and TIS genes in cultured rat astrocytes by neurotransmitters. J Neurosci Res 24:107-114.

Barnes CA, McNaughton BL, Mizumori SJ, Leonard BW, Lin LH (1990) Comparison of spatial and temporal characteristics of neuronal activity in sequential stages of hippocampal processing. Prog Brain Res 83:287-300.

Chawla MK, Guzowski JF, Ramirez-Amaya V, Lipa P, Hoffman KL, Marriott LK, Worley PF, McNaughton BL, Barnes CA (2005) Sparse, environmentally selective expression of Arc RNA in the upper blade of the rodent fascia dentata by brief spatial experience. Hippocampus 15:579-586.

Eriksson PS, Perfilieva E, Bjork-Eriksson T, Alborn AM, Nordborg C, Peterson DA, Gage FH (1998) Neurogenesis in the adult human hippocampus. Nat Med 4:1313-1317.

Esposito MS, Piatti VC, Laplagne DA, Morgenstern NA, Ferrari CC, Pitossi FJ, Schinder AF (2005) Neuronal differentiation in the adult hippocampus recapitulates embryonic development. J Neurosci 25:10074-10086.

Fujioka T, Fujioka A, Duman RS (2004) Activation of cAMP signaling facilitates the morphological maturation of newborn neurons in adult hippocampus. J Neurosci 24:319-328.

Ge S, Goh EL, Sailor KA, Kitabatake Y, Ming GL, Song H (2006) GABA regulates synaptic integration of newly generated neurons in the adult brain. Nature 439:589-593.

Gothard KM, Hoffman KL, Battaglia FP, McNaughton BL (2001) Dentate gyrus and cal ensemble activity during spatial reference frame shifts in the presence and absence of visual input. J Neurosci 21:7284-7292.

Gould E, Beylin A, Tanapat P, Reeves A, Shors TJ (1999) Learning enhances adult neurogenesis in the hippocampal formation. Nat Neurosci $2: 260-265$.

Guzowski JF, McNaughton BL, Barnes CA, Worley PF (1999) Environment-specific expression of the immediate-early gene Arc in hippocampal neuronal ensembles. Nat Neurosci 2:1120-1124.

Guzowski JF, Lyford GL, Stevenson GD, Houston FP, McGaugh JL, Worley PF, Barnes CA (2000) Inhibition of activity-dependent arc protein expression in the rat hippocampus impairs the maintenance of long-term potentiation and the consolidation of long-term memory. J Neurosci 20:3993-4001.

Guzowski JF, Miyashita T, Chawla MK, Sanderson J, Maes LI, Houston FP, Lipa P, McNaughton BL, Worley PF, Barnes CA (2006) Recent behavioral history modifies coupling between cell activity and Arc gene transcription in hippocampal CA1 neurons. Proc Natl Acad Sci USA 103: 1077-1082.

Hastings NB, Gould E (1999) Rapid extension of axons into the CA3 region by adult-generated granule cells. J Comp Neurol 413:146-154.

Jessberger S, Kempermann G (2003) Adult-born hippocampal neurons mature into activity-dependent responsiveness. Eur J Neurosci 18:2707-2712.

Jung MW, McNaughton BL (1993) Spatial selectivity of unit activity in the hippocampus granular layer. Hippocampus 3:165-182.

Kaplan MS, Hinds JW (1977) Neurogenesis in the adult rat: electron microscopic analysis of light radioautographs. Science 197:1092-1094.

Kuhn HG, Dickinson-Anson H, Gage FH (1996) Neurogenesis in the dentate gyrus of the adult rat: age-related decrease of neuronal progenitor proliferation. J Neurosci 16:2027-2033.

McNaughton BL, Mizumori SJ, Barnes CA, Leonard BJ, Marquis M, Green EJ (1994) Cortical representation of motion during unrestrained spatial navigation in the rat. Cereb Cortex 4:27-39.

Overstreet-Wadiche LS, Westbrook GL (2006) Functional maturation of adult-generated granule cells. Hippocampus 16:208-215.

Overstreet-Wadiche LS, Bensen AL, Westbrook GL (2006a) Delayed development of adult-generated granule cells in dentate gyrus. J Neurosci 26:2326-2334
Overstreet-Wadiche LS, Bromberg DA, Bensen AL, Westbrook GL (2006b) Seizures accelerate functional integration of adult-generated granule cells. J Neurosci 26:4095-4103.

Qin YL, McNaughton BL, Skaggs WE, Barnes CA (1997) Memory reprocessing in corticocortical and hippocampocortical neuronal ensembles. Philos Trans R Soc Lond B Biol Sci 352:1525-1533.

Ramirez-Amaya V, Vazdarjanova A, Mikhael D, Rosi S, Worley PF, Barnes CA (2005) Spatial exploration-induced Arc mRNA and protein expression: evidence for selective, network-specific reactivation. J Neurosci 25:1761-1768.

Rao MS, Shetty AK (2004) Efficacy of doublecortin as a marker to analyse the absolute number and dendritic growth of newly generated neurons in the adult dentate gyrus. Eur J Neurosci 19:234-246.

Rao MS, Hattiangady B, Abdel-Rahman A, Stanley DP, Shetty AK (2005) Newly born cells in the ageing dentate gyrus display normal migration, survival and neuronal fate choice but endure retarded early maturation. Eur J Neurosci 21:464-476.

Ribak CE, Korn MJ, Shan Z, Obenaus A (2004) Dendritic growth cones and recurrent basal dendrites are typical features of newly generated dentate granule cells in the adult hippocampus. Brain Res 1000:195-199.

Schmidt-Hieber C, Jonas P, Bischofberger J (2004) Enhanced synaptic plasticity in newly generated granule cells of the adult hippocampus. Nature 429:184-187.

Shen J, Kudrimoti HS, McNaughton BL, Barnes CA (1998) Reactivation of neuronal ensembles in hippocampal dentate gyrus during sleep after spatial experience. J Sleep Res 1:6-16.

Shors TJ (2004) Memory traces of trace memories: neurogenesis, synaptogenesis and awareness. Trends Neurosci 27:250-256.

Shors TJ, Miesegaes G, Beylin A, Zhao M, Rydel T, Gould E (2001) Neurogenesis in the adult is involved in the formation of trace memories. Nature 410:372-376.

Song H, Kempermann G, Overstreet Wadiche L, Zhao C, Schinder AF, Bischofberger J (2005) New neurons in the adult mammalian brain: synaptogenesis and functional integration. J Neurosci 25:10366-10368.

Song HJ, Stevens CF, Gage FH (2002) Neural stem cells from adult hippocampus develop essential properties of functional CNS neurons. Nat Neurosci 5:438-445.

Stanfield BB, Trice JE (1988) Evidence that granule cells generated in the dentate gyrus of adult rats extend axonal projections. Exp Brain Res 72:399-406.

Steward O, Worley PF (2001) Selective targeting of newly synthesized Arc mRNA to active synapses requires NMDA receptor activation. Neuron 30:227-240.

van Praag H, Christie BR, Sejnowski TJ, Gage FH (1999) Running enhances neurogenesis, learning, and long-term potentiation in mice. Proc Natl Acad Sci USA 96:13427-13431.

van Praag H, Schinder AF, Christie BR, Toni N, Palmer TD, Gage FH (2002) Functional neurogenesis in the adult hippocampus. Nature 415:1030-1034.

Vazdarjanova A, McNaughton BL, Barnes CA, Worley PF, Guzowski JF (2002) Experience-dependent coincident expression of the effector immediate-early genes arc and Homer la in hippocampal and neocortical neuronal networks. J Neurosci 22:10067-10071.

Vazdarjanova A, Ramirez-Amaya V, Insel N, Plummer TK, Rosi S, Mikhael D, Worley PF, Guzowski JF, Barnes CA (2006) Spatial exploration induces Arc, a plasticity-related immediate-early gene, only in calcium/ calmodulin-dependent protein kinase II-positive principal excitatory and inhibitory neurons of the forebrain. J Comp Neurol 498:317-329.

Weiss S, Reynolds BA, Vescovi AL, Morshead C, Craig CG, van der Kooy D (1996) Is there a neural stem cell in the mammalian forebrain? Trends Neurosci 19:387-393. 